\title{
UNESTERIFIED FATTY ACID IN HUMAN BLOOD PLASMA ${ }^{1}$
}

\author{
By ROBERT S. GORDON, JR. AND AMELIA CHERKES
}

(From the Laboratory of Metabolism, National Heart Institute, Bethesda 14, Md.)

(Submitted for publication August 5, 1955; accepted October 10, 1955)

The existence of small quantities of unesterified fatty acid in blood plasma has been known for some years. In particular, the finding of unesterified fatty acid (hereafter abbreviated UFA) in albumin fractions prepared from fresh human plasma by the methods of Cohn, Hughes, and Weare (1), and the report of Davis (2) that fresh serum yielded small quantities of UFA, indicate that UFA actually exists as such in plasma and is not a laboratory artifact. In connection with the investigations into the mechanism of lipid transport being carried forward in this laboratory, it had been found $(3,4)$ that a principal product of lipemia clearing in vitro is unesterified fatty acid. Study of the relationship of physiologic clearing in vivo to the concentration of circulating UFA therefore suggested itself, and led to the present investigation.

It will be observed that the term "unesterified fatty acid" is used in preference to "free fatty acid" in spite of the widespread acceptance of the latter in fat and oil chemistry. The choice is due to the evidence (5-7) that higher fatty acids are firmly, though reversibly, bound to serum albumin and at times to other plasma proteins when proteins and fatty acids exist together in aqueous solution. The properties of the fatty acid ions, such as surface activity, are therefore not in evidence when small quantities of these substances are present in serum or plasma (8). We suggest that the term "free" be reserved to describe the fraction of unesterified fatty acid not bound to protein, a fraction which is not measurable by present techniques, but which may later prove to be of biochemical significance.

1 A preliminary report of this material was given at the Gordon Conference of the American Association for the Advancement of Science, Meriden, N. H., June 14, 1955. The subject matter also coincides in part with material being submitted as a thesis to the Department of Biochemistry, Georgetown University, by Miss Cherkes, in partial fulfillment of the requirements for the degree of Master of Science.

\section{MATERIALS AND METHODS}

For this initial investigation, the procedure of Davis (2) for the determination of UFA in blood plasma was employed, with modifications as follows: Blood samples were taken from antecubital veins except where otherwise noted (a tourniquet being applied briefly), treated with solid sodium oxalate $1.5 \mathrm{mg}$. per $\mathrm{ml}$. to prevent clotting, and immediately chilled in ice water. Centrifugation was carried out in the cold, and the extract prepared within four hours. These precautions were intended to reduce in vitro lipolytic action which might cause artifactual elevation of the UFA concentration. Cold storage of normal or lipemic plasma samples for periods of up to four hours has been shown not to result in significant changes of UFA concentrations. To $2 \mathrm{ml}$. of plasma were added, in order, $1 \mathrm{ml}$. phosphate buffer of $\mathrm{pH} 6.0$ and molarity $0.2,1 \mathrm{ml}$. 5 per cent sodium dodecyl sulfate, $9 \mathrm{ml}$. saturated aqueous sodium sulfate, and finally a slight excess of anhydrous sodium sulfate powder. The reagents utilized were of the best commercial grade. Five extractions with 2-ml. portions of ethyl ether were carried out as described by Davis. After gentle evaporation of the ether, the residue was taken up in $5 \mathrm{ml} .95$ per cent alcohol, a drop of approximately .01 normal sulfuric acid was added, and the solution titrated. The titrant was .02 normal sodium hydroxide (aqueous solution) delivered from a Gilmont ultramicroburette. $\mathrm{CO}_{2}$-free air served to stir the solution, and the titration was followed with a Beckman Model G glass electrode $\mathrm{pH}$ meter. Titration between the apparent $\mathrm{pH}$ limits of 6 and 10 was found to give excellent agreement with the known molarities of standard higher fatty acids. After deduction of an appropriate blank, the concentration of UFA in an unknown plasma could be calculated in milliequivalents per liter. The data have not been corrected for the small change in plasma volume due to addition of sodium oxalate. In the course of the work it was noted that the dried fatty acid extracts, when stored in the refrigerator, were quite stable in terms of their acid equivalence. Not more than 24 hours was permitted to elapse, however, between the preparation and titration of the extracts with which this report is concerned.

The human subjects studied in this investigation are from two sources, inpatients at the Clinical Center of the National Institutes of Health (the normals in this group being primarily conscientious objectors), and a number of laboratory employees who had been found healthy in a routine pre-employment medical work-up, and who were free of acute disease on the day of study. 
TABLE I

Recovery of fatty acids from plasma

\begin{tabular}{lcr}
\hline \hline & $\begin{array}{c}\text { Amount } \\
\text { added } \\
m E q . / L .\end{array}$ & $\begin{array}{c}\text { Recovery } \\
\%\end{array}$ \\
\hline Acid & 0.91 & 99,103 \\
Stearic & 0.90 & 96,97 \\
Palmitic & 0.89 & 98,103 \\
Myristic & 0.84 & 99,102 \\
Lauric & 0.93 & 101,96 \\
Capric & 0.99 & 85,87 \\
Caprylic & 1.33 & 33,32 \\
Caproic & 0.63 & 2,8 \\
Butyric & 1.15 & Less than 1 \\
Propionic & 1.08 & 80,82 \\
Linoleic & 1.06 & 84,85 \\
Linolenic & 0.80 & 98,98 \\
Oleic & & \\
\hline
\end{tabular}

OBSERVATIONS

It was deemed necessary initially to confirm the validity of the method of analysis; Davis' original paper (2) does not provide proof that the procedure is quantitatively accurate. Recovery experiments were therefore carried out by adding small amounts of fatty acids to a plasma whose UFA had already been determined. The results of this study are shown in Table I. The recovery of all the higher fatty acids was excellent with the exception of the polyunsaturated compounds, with which a loss of approximately twenty per cent occurred. This loss, even if not due to contamination of the acid samples with foreign acidic substances, is felt to be too small to detract appreciably from the studies which follow.

Of the substances which might be expected to interfere, all but two could be eliminated from consideration. Some phospholipids have a titratable acid group; their presence in the extract might be expected to lead to inaccuracies. Extracts prepared as described from normal plasmas, however, were consistently found to contain only negligible traces of lipid phosphorus. A number of carboxylic acid anions were added to plasmas in recovery experiments. Of these, oxalate, citrate, ethylenediaminetetraacetate, ascorbate, urate, lactate, pyruvate, and acetoacetate were found not to interfere. Beta-hydroxybutyrate behaved like butyrate, with 7 per cent of the added material being recovered, whereas in the case of cholate, a recovery of 23 per cent was noted. In each case, the per cent recovered was independent of the amount added over a wide range of concentrations. It therefore appears that these two acids, which are so similar to the fatty acids in their solubility and titration properties, may contribute somewhat to the UFA value as determined by this procedure. The contribution must be a minor one, however, unless the concentrations of these substances which have been reported in human blood plasma are grossly underestimated.

In a considerable number of instances, analyses by this method on normal plasma samples taken under various conditions were performed in duplicate. Statistical analysis of these data reveals that the method itself has an intrinsic standard error of $0.061 \mathrm{mEq}$. per L. (exclusive, of course, of possible systematic errors). Because the biologic variations encountered in the subsequent study so greatly exceeded the variance of the analytical method, it was deemed advisable not to attempt to do all analyses in duplicate, but rather to increase the number of subjects studied. For the same reason, in the study of the effect of various stimuli on the UFA concentration, the technique of following serial samples in each subject, and so of using each individual as his own control, was adopted. The data will be presented in graphic form so that the course of each subject can be followed.

The first study to be undertaken was an investigation of the effect of oral fat feeding on the UFA concentration. Subjects for this study were on a normal diet; they ate no food after supper on the day preceding the test. After a fasting blood specimen had been obtained, the subjects ingested a palatable breakfast containing $100 \mathrm{gm}$. fat (sup-

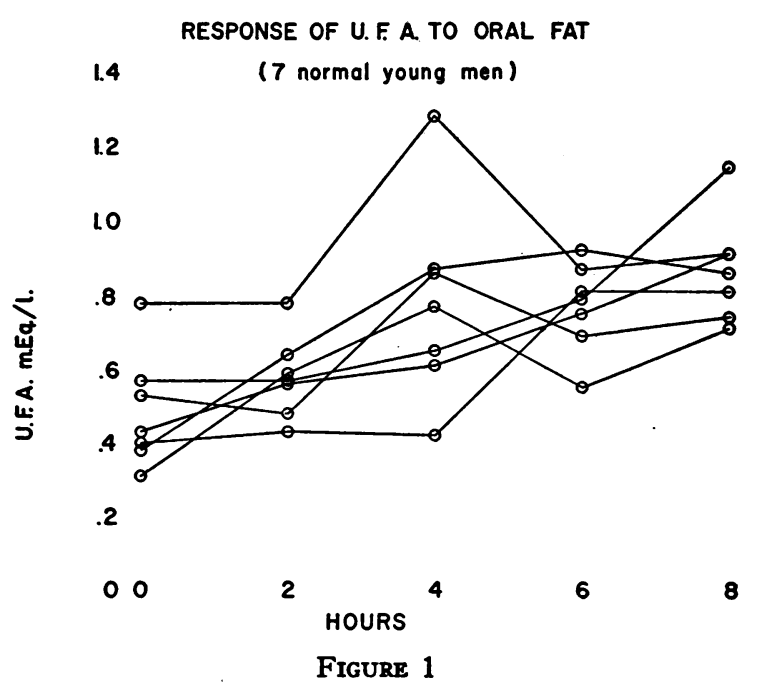


plied in eggs, bacon, cream, and oleomargarine), $40 \mathrm{gm}$. protein, and negligible carbohydrate. Samples were taken at two-hour intervals for eight hours, the subjects having no further nourishment during the day. To complement the UFA determinations, total lipid analyses were performed according to the method of Bragdon (9). The effect of the fat feeding on the UFA values is shown in Figure 1. It will be noted that in only three out of seven instances was there a rise in UFA concentration followed by a fall, and in each of these the final UFA level appreciably exceeded the initial value. When the UFA and total lipid values for each individual were compared, it was found that the peak of lipemia, usually at four hours, did not necessarily coincide with the highest UFA value, but rather that UFA often continued to rise after clearing of lactescence and of chemically measured lipemia was complete.

For comparison with the effect of oral fat feeding, the effect of fasting was studied in normal young subjects, many of them the same individuals that had been used in the fat-feeding studies. The procedure was identical, except that the breakfast was omitted, and the fast was terminated after 4 or 6 hours of observation (18 to 22 hours' total fasting). The data are presented in Figure 2. Of course no lipemia was present, but the UFA values fall in the same range as those observed after fat feeding, and showed a tendency to rise gradually as fasting continued.

The effect of feeding carbohydrate was next studied by observing the response of UFA values

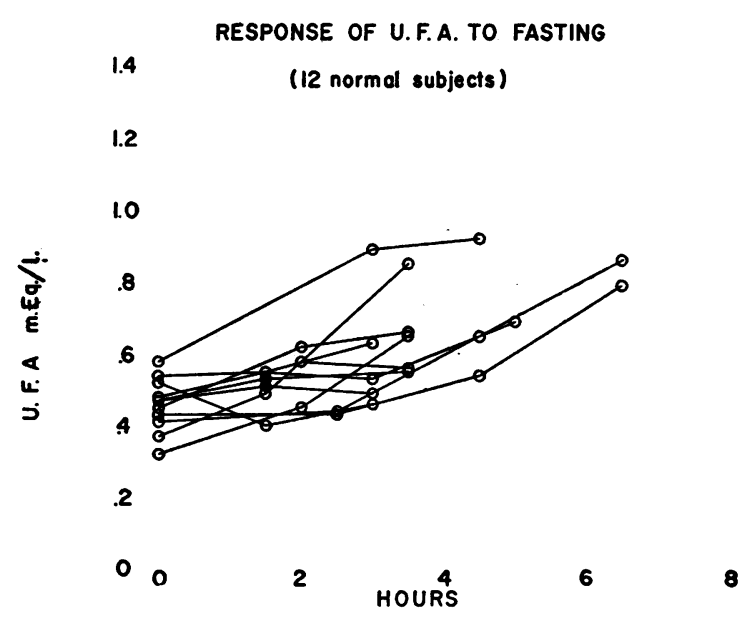

Figure 2

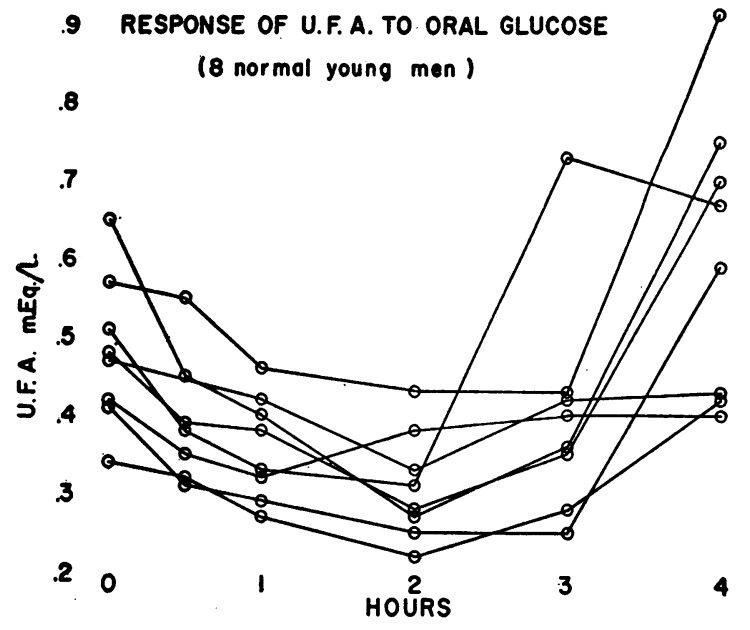

FIgURe 3

to the standard oral glucose tolerance test, a dose of $100 \mathrm{gm}$. being used. The results for eight normal young men appear in Figure 3. In addition, it was possible to obtain blood samples during glucose tolerance tests performed for other reasons on seven hospital patients, subjects who suffered from a variety of chronic illnesses not related to carbohydrate metabolism, and whose blood sugar curves were not abnormal. In each of these 15 instances, the UFA value dropped decidedly below the control level one or two hours after the glucose feeding. It should be noted in Figure 2 that spontaneous falls in UFA concentration occurred only rarely during fasting, and were never of great magnitude; the uniformity of the response to carbohydrate feeding is therefore impressive. At-

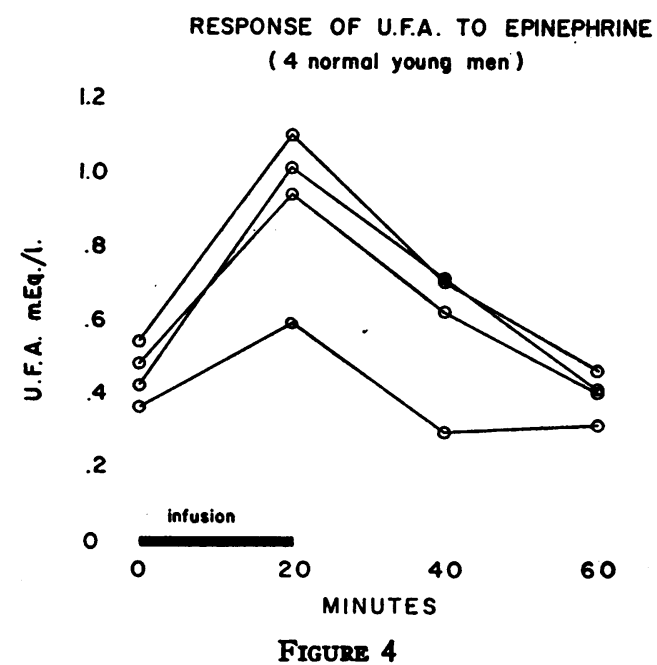

Figure 4 
TABLE II

Extraction of unesterified fatty acids

\begin{tabular}{|c|c|c|c|c|c|c|}
\hline Patient & $\begin{array}{l}\text { Venous } \\
\text { sample }\end{array}$ & $\begin{array}{l}\text { Venous } \\
\text { UFA }\end{array}$ & $\begin{array}{c}\text { Simultaneous } \\
\text { arterial } \\
\text { UFA }\end{array}$ & $\begin{array}{l}\text { A-V } \\
\text { diff. }\end{array}$ & $\begin{array}{c}\text { A-V } \mathrm{O}_{2} \\
\text { diff. }\end{array}$ & $\begin{array}{c}\% \text { of } \mathrm{O}_{2} \\
\text { to oxidize } \\
\text { UFA }\end{array}$ \\
\hline A. E. & $\begin{array}{l}\text { Coronary } \\
\text { Sinus }\end{array}$ & $\begin{array}{c}m E q . / L . \\
0.64 \\
0.69\end{array}$ & $\begin{array}{c}m E q . / L . \\
0.85 \\
0.87\end{array}$ & 0.19 & $\begin{array}{c}\text { ool. \% } \\
10.6\end{array}$ & 70 \\
\hline W. V. & $\begin{array}{l}\text { Coronary } \\
\text { Sinus }\end{array}$ & $\begin{array}{l}0.77 \\
0.77\end{array}$ & $\begin{array}{l}0.80 \\
0.79\end{array}$ & 0.03 & 14.4 & 7 \\
\hline M. L. & $\begin{array}{l}\text { Coronary } \\
\text { Sinus }\end{array}$ & $\begin{array}{l}0.69 \\
0.71\end{array}$ & $\begin{array}{l}0.89 \\
0.90\end{array}$ & 0.19 & $\begin{array}{c}\text { Lost } \\
\text { (Normally } \\
10-12)\end{array}$ & $\begin{array}{c}\text { (Probably } \\
\text { 50-60) }\end{array}$ \\
\hline R. B. & $\begin{array}{l}\text { Coronary } \\
\text { Sinus }\end{array}$ & $\begin{array}{l}0.68 \\
0.61\end{array}$ & $\begin{array}{l}0.76 \\
0.75\end{array}$ & 0.11 & 13.7 & 25 \\
\hline L. S. & $\begin{array}{l}\text { Coronary } \\
\text { Sinus }\end{array}$ & $\begin{array}{l}0.46 \\
0.42\end{array}$ & $\begin{array}{l}0.64 \\
0.63\end{array}$ & 0.20 & 12.2 & 55 \\
\hline S. M.* & $\begin{array}{l}\text { Coronary } \\
\text { Sinus }\end{array}$ & $\begin{array}{l}0.76 \\
0.75\end{array}$ & $\begin{array}{l}0.94 \\
0.98\end{array}$ & 0.20 & 14.8 & 42 \\
\hline $\begin{array}{l}\text { S. M.* } \\
\text { (After } \\
\text { glucose) }\end{array}$ & $\begin{array}{l}\text { Coronary } \\
\text { Sinus }\end{array}$ & $\begin{array}{l}0.32 \\
0.29\end{array}$ & $\begin{array}{l}0.32 \\
0.30\end{array}$ & 0.00 & 12.4 & 0 \\
\hline L. S. & $\begin{array}{c}\text { Hepatic } \\
\text { Vein }\end{array}$ & $\begin{array}{l}0.53 \\
0.51\end{array}$ & $\begin{array}{l}0.55 \\
0.54\end{array}$ & 0.03 & 3.4 & 30 \\
\hline E. H. & $\begin{array}{c}\text { Hepatic } \\
\text { Vein }\end{array}$ & $\begin{array}{l}0.65 \\
0.62\end{array}$ & $\begin{array}{l}0.85 \\
0.82\end{array}$ & 0.20 & Lost & \\
\hline F. V. & $\begin{array}{c}\text { Hepatic } \\
\text { Vein }\end{array}$ & $0.81^{\circ}$ & 0.98 & 0.17 & 7.5 & 70 \\
\hline W. H. & $\begin{array}{l}\text { Internal } \\
\text { Jugular }\end{array}$ & $\begin{array}{l}0.69 \\
0.69\end{array}$ & $\begin{array}{l}0.74 \\
0.71\end{array}$ & 0.04 & & \\
\hline J. B. & $\begin{array}{l}\text { Internal } \\
\text { Jugular }\end{array}$ & $\begin{array}{l}1.35 \\
1.34\end{array}$ & $\begin{array}{l}1.35 \\
1.35\end{array}$ & 0.00 & & \\
\hline F.F. & $\begin{array}{l}\text { Pulmonary } \\
\text { Artery }\end{array}$ & $\begin{array}{l}1.25 \\
1.29\end{array}$ & $\begin{array}{l}1.24 \\
1.23\end{array}$ & -0.03 & & \\
\hline A. $\mathrm{H}$. & $\begin{array}{l}\text { Pulmonary } \\
\text { Artery }\end{array}$ & $\begin{array}{l}0.99 \\
0.97\end{array}$ & 1.05 & 0.07 & & \\
\hline L. S. & $\begin{array}{l}\text { Pulmonary } \\
\text { Artery }\end{array}$ & $\begin{array}{l}0.61 \\
0.64\end{array}$ & $\begin{array}{l}0.64 \\
0.61\end{array}$ & 0.00 & & \\
\hline F. V. & $\begin{array}{l}\text { Pulmonary } \\
\text { Artery }\end{array}$ & 0.99 & 0.95 & -0.04 & & \\
\hline F. V. & $\begin{array}{l}\text { Superior } \\
\text { Vena Cava }\end{array}$ & $\begin{array}{l}0.83 \\
0.85\end{array}$ & $\begin{array}{l}0.77 \\
0.77\end{array}$ & -0.07 & & \\
\hline A. $\mathrm{H}$. & $\begin{array}{l}\text { Superior } \\
\text { Vena Cava }\end{array}$ & $\begin{array}{l}0.93 \\
0.97\end{array}$ & $\begin{array}{l}0.93 \\
0.96\end{array}$ & 0.00 & & \\
\hline F. V. & $\begin{array}{l}\text { Inferior } \\
\text { Vena Cava }\end{array}$ & $\begin{array}{l}0.96 \\
0.96\end{array}$ & $\begin{array}{l}0.83 \\
0.85\end{array}$ & -0.12 & & \\
\hline
\end{tabular}

* INITIAL samples obtained in fasting state. With the catheter remaining in place, an infusion of $50 \mathrm{gm}$. glucose and 6 units of crystalline insulin was administered. The second samples were taken after 30 minutes. 
tempts to derive a quantitative relationship between the numerical values of UFA and blood sugar were unsuccessful.

In two normal young men, an attempt was made to elicit a drop in UFA concentration by feeding glucose at the peak of a previously induced alimentary lipemia. In each case, a clear-cut drop in UFA occurred, but because of the variability of the response, it is not possible with this limited experience to compare the magnitude of the UFA decrease so induced with that occurring after feeding of glucose alone.

The sharp increase of UFA occurring in many subjects between three and four hours after glucose suggested a relationship to reactive hypoglycemia, although these subjects were not consistently those with the lowest sugar values. It therefore appeared desirable to investigate the effects on UFA of hormones concerned with blood sugar regulation. The response of UFA values to the infusion of 1 milligram of epinephrine intravenously over a twenty-minute period has been followed in four normal young men, the results being shown in Figure 4. It is evident that epinephrine administration resulted in a considerable, but short-lived elevation of the circulating UFA level. Two subjects were tested with the same dose administered subcutaneously with similar, but less dramatic, results. Other hormones affecting glucose metabolism are to be tested in the future.

The work of Lever, Smith, and Hurley $(10,11)$ and of Herbst and Hurley (12) leaves little doubt that intravenous administration of heparin in the presence of lipemia liberates considerable quantities of unesterified fatty acid, though their results may be due in part to in vitro lipolysis occurring in the samples prior to analysis. Grossman, Palm, Becker, and Moeller (13) have reported also that heparin injection in rats causes an increase in petroleum ether-soluble acid, which they believe to represent UFA. It appeared desirable to recheck this observation in humans with the present method, using the precautions which have been enumerated to minimize, if not to eliminate, in vitro lipolysis. This procedure was carried out in eight subjects, four of whom suffered from idiopathic hyperlipemia. The doses of heparin ranged from 10 to 50 milligrams. In every case but one, a normal who had fasted over- night, there was a significant increase in UFA ten minutes after heparin injection.

As will be explained subsequently, the foregoing observations suggested that arteriovenous differences in UFA concentration might be discovered if sought. Specimens of blood from various parts of the human vascular system were therefore obtained during cardiac catheterizations being carried out for the diagnosis of organic heart disease, and during measurements of cerebral blood flow. Patients undergoing these procedures were inpatients on the medical and surgical wards of the Clinical Center; the majority had some structural cardiac lesion or had had such a lesion corrected by surgery. All were fasting at the time of study, and none was critically ill, in congestive failure, or suffering from a complicating metabolic disorder. The results obtained to date are summarized in Table II, in which are tabulated arteriovenous differences of UFA encountered in various areas and, where available, the simultaneous arteriovenous oxygen difference. By assuming a molecular weight for the fatty acids, and further assuming that all the metabolically active UFA in whole blood is carried in the plasma, a calculation can be made of the percentage of the tissue oxygen uptake which would be required to effect the complete oxidation of the fatty acids simultaneously extracted. This figure, calculated for fatty acids of average molecular weight 275 , is given in the last column of Table II.

\section{DISCUSSION}

These data must be taken with certain reservations due to the imperfection of the analytical method used. The main points of interest, however, are not so much the absolute values of UFA as the changes and differences. These differences cannot reasonably be attributed to interfering substances; they must reflect, at least semi-quantitatively, variations in the circulating UFA concentration.

The experimental work which has been presented indicates that the circulating concentration of unesterified fatty acid is in some way related to the nutritional state of the subject. If the energy requirements of the moment are satisfied by carbohydrate, the UFA concentration drops to a low level, whereas if they are not satisfied by in- 
gested foodstuffs, the level rises progressively (at least over the period of observation, which has not been long enough to assure total depletion of hepatic glycogen stores). The effect of oral fat feeding on UFA concentration has not been established with certainty; our data do not suffice to demonstrate an effect of fat feeding that differs from the effect of fasting over the same period.

The rapidity with which the UFA concentration may fluctuate in an individual as his nutritional state varies implies that this may be a material of great metabolic activity. Our data appear to indicate that the concentration of UFA rises in relation to the need (in the case of epinephrine, the anticipated need) for fat as an energy-yielding substrate for oxidative catabolism. The similarity between its behavior and that of the keto acids also served to suggest that it might be directly concerned with the oxidative metabolism of lipids. The hypothesis was therefore formulated that unesterified fatty acid represents the blood lipid fraction which is immediately available to cells in general as a supply of lipid to meet energy demands, and that its release into the blood is regulated by some mechanism sensitive to the need for fat oxidation. This hypothesis led to the study of arteriovenous differences in UFA concentration, and, in turn, is considerably supported by those results.

A study of the data in Table II enables several conclusions to be drawn. There can be little doubt that the fasting myocardium extracts from the perfusing blood a considerable quantity of titratable acidity, and, if our assumption that this material is fatty acid of average molecular weight 275 is correct, the fatty acids so extracted suffice to supply the bulk of the energy requirements of the myocardium (as measured by simultaneous oxygen consumption). In the one patient in which such a study has been possible, the administration of glucose and insulin intravenously completely abolished the myocardial UFA extraction. This finding is entirely consistent with the presently accepted concept that glucose is the preferred substrate when it is available. The hepatic vein samples that have been obtained make it reasonably certain that, in addition to myocardium, the splanchnic area participates in the extraction of UFA from the blood. The two measurements of arteriovenous UFA differences in the cerebral cir- culation that we have had the opportunity to perform are consonant with the belief that brain tissue does not oxidize appreciable quantities of fat.

Since many tissues appear to extract UFA from the blood, it is necessary that the material be released into the blood elsewhere in order to maintain an arterial level. Lung would not seem likely as a source of UFA, and the pertinent measurements to date indicate that lung neither adds nor extracts an appreciable amount of UFA. The source would appear to be peripheral in view of the finding of superior and inferior vena caval UFA levels which exceeded the arterial concentrations. It is entirely reasonable to suppose, on the basis of present evidence, that adipose tissue is the source of the circulating UFA, since it contains the fat stores which must be mobilized and consumed during prolonged fasting. In the light of the recent demonstration by Korn and Quigley (14) of the existence of lipoprotein lipase (clearing factor) in the adipose tissue of rats, and their as yet unpublished preliminary evidence that the same or a similar enzyme exists in human adipose tissue, the supposition becomes even more attractive.

The question with which the investigation began, then, can be answered only tentatively at this time. Circulating UFA concentrations may well reflect the activity of lipoprotein lipase located in tissues and releasing lipid into the general circulation in this form for catabolism. Whether or not the process of clearing an alimentary lipemia contributes to the circulating UFA concentration remains in doubt, but it seems clear that the concentration cannot be taken as an index of the activity of the clearing process, since administration of glucose, which does not prevent the clearing of lipemia, causes a sharp drop in the UFA level. It is also apparent that high levels of circulating UFA may occur under conditions in which lipemia is minimal, and the clearing process inactive.

\section{SUMMARY}

The concentration of unesterified fatty acid (UFA) has been measured in human blood plasma by the method of Davis, which has been found to be approximately quantitative for this purpose. The UFA values fluctuate rapidly and markedly 
from time to time in normal individuals. The values tend to rise after ingestion of fat, but rise similarly on fasting, so that lipemia per se cannot be shown to be correlated with increase in UFA. Carbohydrate feeding produces a uniform fall, whereas epinephrine injection causes an increase. The hypothesis is offered that UFA is the blood lipid fraction primarily concerned with the supply of fats to tissues for oxidative metabolism. The extraction of this substance by tissues has been demonstrated, and evidence suggesting its origin in adipose tissue obtained.

\section{ACKNOWLEDGMENTS}

The authors are indebted to Dr. Joseph Bragdon for the analyses for total lipid and lipid phosphorus, and to Mr. Fred Bullock for oxygen content determinations. We also wish to thank the many members of the Staff of the Clinical Center who made patients available to us for study and particularly those who assisted in obtaining blood specimens.

\section{REFERENCES}

1. Cohn, E. J., Hughes, W. L., Jr., and Weare, J. H., Preparation and properties of serum and plasma proteins. XIII. Crystallization of serum albumins from ethanol-water mixtures. J. Am. Chem. Soc., 1947, 69, 1753.

2. Davis, B. D., The estimation of small amounts of fatty acid in the presence of polyoxyethylene sorbitan partial fatty acid esters ("Tween") and of serum proteins. Arch. Biochem., 1947, 15, 351.

3. Gordon, R. S., Jr., Boyle, E., Brown, R. K., Cherkes, A., and Anfinsen, C. B., Role of serum albumin in lipemia clearing reaction. Proc. Soc. Exper. Biol. \& Med., 1953, 84, 168.

4. Korn, E. D., Properties of clearing factor obtained from rat heart acetone powder. Science, 1954, 120, 399.

5. Teresi, J. D., and Luck, J. M., The combination of organic anions with serum albumin. VIII. Fatty acid salts. J. Biol. Chem., 1952, 194, 823.

6. Klotz, I. M., and Ayers, J., Protein interactions with organic molecules. Disc. Faraday Soc., 1953, 13, 189.

7. Gordon, R. S., Jr., Interaction between oleate and the lipoproteins of human serum. J. Clin. Invest., 1955, 34, 477.

8. Lecomte du Nouy, P., Surface Equilibria of Biological and Organic Colloids. New York Chem. Catalog. Co., 1926, p. 155 et seq.

9. Bragdon, J. H., Colorimetric determination of blood lipides. J. Biol. Chem., 1951, 190, 513.

10. Lever, W. F., Smith, P. A. J., and Hurley, N. A., Effects of intravenous heparin on the plasma lipoproteins in primary hypercholesteremic xanthomatosis and idiopathic hyperlipemia. Science, 1953, 118, 653.

11. Lever, W. F., Smith, P. A. J., and Hurley, N. A., Idiopathic hyperlipemia and primary hypercholesteremic xanthomatosis. III. Effects of intravenously administered heparin on the plasma proteins and lipids. J. Invest. Dermatol., 1954, 22, 71.

12. Herbst, F., and Hurley, N., Effects of heparin on alimentary hyperlipemia. An electrophoretic study. J. Clin. Invest., 1954, 33, 907.

13. Grossman, M. I., Palm, L., Becker, G. H., and Moeller, H. G., Effect of lipemia and heparin on free fatty acid content of rat plasma. Proc. Soc. Exper. Biol. \& Med., 1954, 87, 312.

14. Korn, E. D., and Quigley, T. W., Jr., Studies on lipoprotein lipase of rat heart and adipose tissue. Biochim. et Biophys. Acta, 1955, 18, 143. 